\title{
Volume Management and Resuscitation in Colorectal Surgery
}

\author{
David R. A. Yates · Simon J. Davies • \\ Samantha R. Warnakulasuriya $\cdot$ R. Jonathan T. Wilson
}

Published online: 3 September 2014

(c) Springer Science + Business Media New York 2014

\begin{abstract}
The maintenance of intravascular volume during and after colorectal surgery is important in the optimization of perioperative outcomes. Techniques for optimizing cardiac output using minimally invasive monitoring have been studied extensively with many authorities now advocating some form of intraoperative stroke volume optimization. The excess administration of crystalloid solutions causes significant postoperative morbidity yet recent trials investigating the optimal type of fluid to be used have failed to show any benefit from the administration of colloids over crystalloids. Saline-based fluids are known to cause metabolic disturbance in the form of hyperchloraemia and acidosis but until recently no outcome data on their use was available. Large-scale observational studies now suggest that balanced solutions carry significant benefits when compared to saline-based solutions. This article reviews the recent literature describing the controversies in perioperative fluid management in colorectal surgery.
\end{abstract}

Keywords Perioperative fluid therapy - Crystalloid · Colloid · Haemodynamic monitoring · Covert hypovolaemia $\cdot$ Colorectal surgery

D. R. A. Yates $(\bowtie) \cdot$ S. J. Davies · S. R. Warnakulasuriya

R. J. T. Wilson

Department of Anaesthesia, York Teaching Hospital NHS

Foundation Trust, Wiggington Road, York YO31 8HE, UK

e-mail: david.yates@york.nhs.uk

S. J. Davies

e-mail: simon.davies@york.nhs.uk

S. R. Warnakulasuriya

e-mail: swarnak84@gmail.com

R. J. T. Wilson

e-mail: jonathan.rjt.wilson@york.nhs.uk

\section{Introduction}

Intravenous fluid therapy plays an important role in the management of patients undergoing major colorectal surgery. Optimal fluid therapy, or rather the attainment of euvolaemia, describes the state of a 'normal' circulating volume that allows the patient to achieve a cardiac output, and ultimately an oxygen delivery, that meets their current demand [1]. Oxygen demands change, however, particularly during major surgery [2], and hence appropriate fluid management to help meet these needs is a key part of patient management. This dynamic relationship was described by Bellamy as a U-shaped curve comparing complications with administered fluid volumes in the perioperative period and highlighted the relative dangers of hypo- and hypervolaemia [3]. The challenge, however, is to find the ideal amount of fluid for each individual patient, and various techniques have been suggested ranging from liberal or restrictive fluid regimes [4-11], zero balance in the perioperative period [12], and fluid optimisation either targeting oxygen delivery or maximising strove volume [13-20]. In addition there has been much interest into the effect of the type of fluid administered and its effects on postoperative outcomes $[21,22 \bullet, 23 \bullet, 24]$. This review article will examine current areas of interest in this field.

\section{Oxygen Delivery in the Perioperative Period}

Major surgery generates a significant neuroendocrine and inflammatory response, ultimately leading to an increase in tissue oxygen consumption. The ability to meet those increased requirements has been shown to predict outcome following major surgery. Shoemaker observed that the magnitude and duration of oxygen debt was significantly 
higher in non-survivors of major surgery [25], and that targeting perioperative oxygen delivery to supranormal values of $600 \mathrm{ml} / \mathrm{min} / \mathrm{m}^{2}$ through various interventions including fluid and inotrope administration lead to increased survival [26]. There appears to be an association between postoperative complications and the development of an oxygen debt and whilst complication rates can be reduced if stroke volume and oxygen delivery are augmented to minimize the development of this debt, the exact mechanisms behind these improvements are not fully understood. Several randomized controlled trials have shown this approach to be beneficial and now form the basis of what has been described as 'Goal Directed Therapy' $[27,28]$.

Colorectal surgery presents a unique challenge to the anaesthetist in that a significant proportion of surgery results in the creation of a bowel anastomosis. The integrity of anastomoses is dependent on adequate oxygen delivery and therefore blood flow. Neural mechanisms to maintain oxygen homeostasis may be compromised during and after surgery, and hence oxygen delivery becomes entirely flow dependent. Unfortunately the splanchnic circulation is extremely susceptible to hypovolaemia and blood flow to the gut decreases out of proportion to any overall reduction in cardiac output. This reduction to susceptible organs in the face of otherwise normal haemodynamics may be termed 'covert hypovolaemia'.

\section{Iatrogenic Injury Due to Fluid Administration}

\section{Hypovolaemia}

Overt hypovolaemia is clinically recognizable by hypotension, tachycardia, cool extremities and a narrow pulse pressure, and unless the circulating volume is rapidly corrected patients will develop organ dysfunction and ultimately failure. Overt hypovolaemia is readily detectable and infrequent in the intraoperative period.

Covert hypovolaemia, however, is considerably more difficult to quantify and detect, and may be more common than we first realise. Despite promotion of adequate preoperative fluid intake, and the avoidance of bowel preparation many patients present for surgery with some degree of fluid deficit. Whilst they can still maintain an adequate oxygen delivery, vasodilatation due to anaesthesia, fluid shifts or blood loss during surgery may disrupt the balance between oxygen supply and demand due to an absolute (fluid loss) and relative (vasodilation) hypovolaemic state. The situation is characterized by a reduction in mean systemic pressure, and hence a reduction in stroke volume. Whilst fit patients may be able to cope with this reduction in oxygen delivery by compensatory mechanisms, patients with limited cardiac reserve are unable to, and enter a state of chronic tissue hypoperfusion- covert hypovolaemia. It is interesting to note that a $17 \%$ reduction in circulating volume leads to only a $10 \%$ reduction in central volume, yet the splanchnic volume is reduced by $40 \%[29,30]$, highlighting how easily this important circulation can be comprised in the perioperative period.

\section{Hypervolaemia}

Excess administration of intravenous fluid in the perioperative period is also associated with significant morbidity [7, 31-35]. In extremis, excess fluid may overwhelm a compromised myocardium leading to heart failure and pulmonary oedema [35]. In a similar vein to covert hypovolaemia, less obvious over hydration may not be immediately apparent but its effects may manifest several days after surgery. Increased extravascular fluid in the lungs compromises gas exchange and increases the risk of pulmonary infection and respiratory failure. Oedema at the site of a bowel anastomosis will impede blood flow and therefore oxygen delivery and in animal models has been shown to contribute to anastomotic failure [36, 37]. Global gut oedema may lead to ileus, and is poorly recognized as a cause of intra-abdominal compartment syndrome [38, 39].

In addition excessive administration of fluids may also interfere with coagulation [40].

\section{Fluid Management Strategies}

The importance of euvolaemia, and the avoidance of hypoor hypervolaemia has led many researchers to examine the optimal method by which to administer intravenous fluids. Fluid management determined by optimisation of stroke volume, targeting of oxygen delivery, or the use of preload responsiveness parameter such as stroke volume variation (SVV) have been advocated [28, 41, 42]. In addition to haemodynamic optimisation there have been a variety of attempts to improve perioperative outcomes using fixed fluid regimes, sometimes referred to as 'liberal' or 'restrictive'.

\section{Liberal versus Restricted Fluid Therapy}

Several studies have examined the effects of liberal or restrictive fluid regimes on postoperative outcomes and conflicting results have been obtained [4-11, 43]. Some studies have shown a benefit with a restrictive approach whilst others favour more liberal fluid administration.

There may be many reasons for this observation. Strategies of fluid management are inconsistent throughout the 
different studies, both in terms of volume, type, and duration of fluid therapy. The inconsistencies seen in terms of the relative merits of either strategy can be understood based on the underlying principle involved, in which a liberal or restrictive policy with a preset fluid regime for a cohort assumes, incorrectly, that all patients may be 'fluid optimized' with the same volume of fluid, so it is not surprising that conflict exists within the studies.

A recent meta-analysis examining liberal versus restrictive regimes showed no difference in mortality between the two approaches, however, there was a significant increase in the incidence of pneumonia $(\mathrm{RR}=2.2$, $95 \%$ CI $1.0-4.5, p=0.04)$ and pulmonary oedema $(\mathrm{RR}=3.8,95 \%$ CI 1.1-13, $p=0.03)$ in the liberal group. This analysis also showed a reduction in time to first bowel movement (Mean Difference 0.8 day, $95 \%$ CI 0.1-1.5), passage of flatus (MD 0.5 day, $95 \%$ CI 0.1-1) and length of hospital stay (MD 2 days, $95 \%$ CI 0.5-3.4) in the restrictive group [44].

On balance it appears that excess administration of intravenous fluid, be it crystalloid or colloid, leads to worse outcomes in colorectal patients. Whether a truly restrictive regime is beneficial remains to be proved and an approach that many authors now deem to be the gold standard for fluid therapy in colorectal surgery is that of individualized stroke volume guided fluid administration.

\section{Stroke Volume Guided Fluid Management}

Original studies of the optimization of oxygen delivery during the perioperative period showed significant benefit in terms of reduced morbidity and mortality $[13,14]$, that possibly had effects long after the surgical episode [45]. Pulmonary artery catheters were used to measure cardiac output and a combination of fluids and inotropes were used to achieve 'supranormal' values of oxygen delivery. Since the publication of these studies the utility of the PA catheter in the high-risk surgical population has been called into doubt and its use has declined significantly [46-48]. Many authorities would argue nowadays that it should only be used in the highest risk patient undergoing major surgery but it is worth noting that as the colorectal surgical population ages and becomes frailer their use may well be appropriate in certain subgroups.

As an alternative to the PA catheter new technology has been developed to measure stroke volume and cardiac output. Several minimally invasive cardiac output monitors are now available which utilize a variety of techniques to assess cardiac output and preload responsiveness. The two technologies with the largest evidence base in colorectal practice are the oesophageal Doppler, and monitors which use the arterial waveform to calculate these parameters.
Oesophageal Doppler (OD)

The OD has the largest evidence base supporting its use in the colorectal population. Several trials to date have shown an outcome benefit in terms of a quicker return of gastrointestinal function, reduced length of stay, and reduced complications when it is used in a protocolised manner [15-19]. The OD utilises ultrasound and relies upon the Doppler principle, that being the velocity of an object is proportional to the shift in its reflected frequency. This principle is used to measure blood flow velocity in the descending thoracic aorta, which is then converted into a measurement of stroke volume via a nomogram.

A 200-250 ml fluid bolus can then be administered and the stroke volume observed. A rise in stroke volume of $\geq 10 \%$ suggests that the ventricle is fluid responsive and the fluid bolus should be repeated. Similarly, if the stroke volume should fall by $10 \%$ it can be rechallenged.

Another important measure is the corrected flow time (FTc). This is a measure of the left ventricular ejection time corrected to a heart rate of $60 \mathrm{bpm}$. Fluid administration algorithms using the OD require the FTc to be less than $350 \mathrm{~ms}$ before fluid should be administered. This is extremely important as algorithms where this is not incorporated have led to harm from over infusion [49].

Transoesophageal echocardiography has been used by anaesthetists during cardiac surgery for many years now with great success. It allows direct visualization and measurement of left ventricular filling and function and has excellent accuracy and precision when compared to the pulmonary artery catheter $[50,51]$. There is, as yet, little evidence to support its use in the colorectal setting but given the evidence base behind the oesophageal Doppler, which estimates stroke volume, the use of a technology with greater accuracy would seem entirely appropriate.

\section{Arterial Waveform Analysis}

There are various monitors which provide an estimate of stroke volume based on algorithms which analyse the arterial waveform, and hence can be used to optimise subjects in a manner similar to the OD [52, 53].

Additional information on fluid status is also provided in the form of SVV or pulse pressure variation (PPV). This describes the variation in the stroke volume or pulse pressure (expressed as a percentage) caused by the change in intrathoracic and intrapleural pressure over a mechanically ventilated respiratory cycle and essentially assigns a numerical value to the phenomenon of the 'swing on the arterial line' (Fig. 1).

An SVV $>10 \%$ has been reported to have approximately 85-90\% sensitivity and specificity for predicting fluid responsiveness. The figure for PPV ranges from 10 to 
Fig. 1 The effect of mechanical ventilation on haemodynamics. Changes in left ventricular stroke volume are due mainly to the drop in RV filling and therefore output during inspiration. Left ventricular stroke volume is maximal at the end of inspiration and minimal during expiration

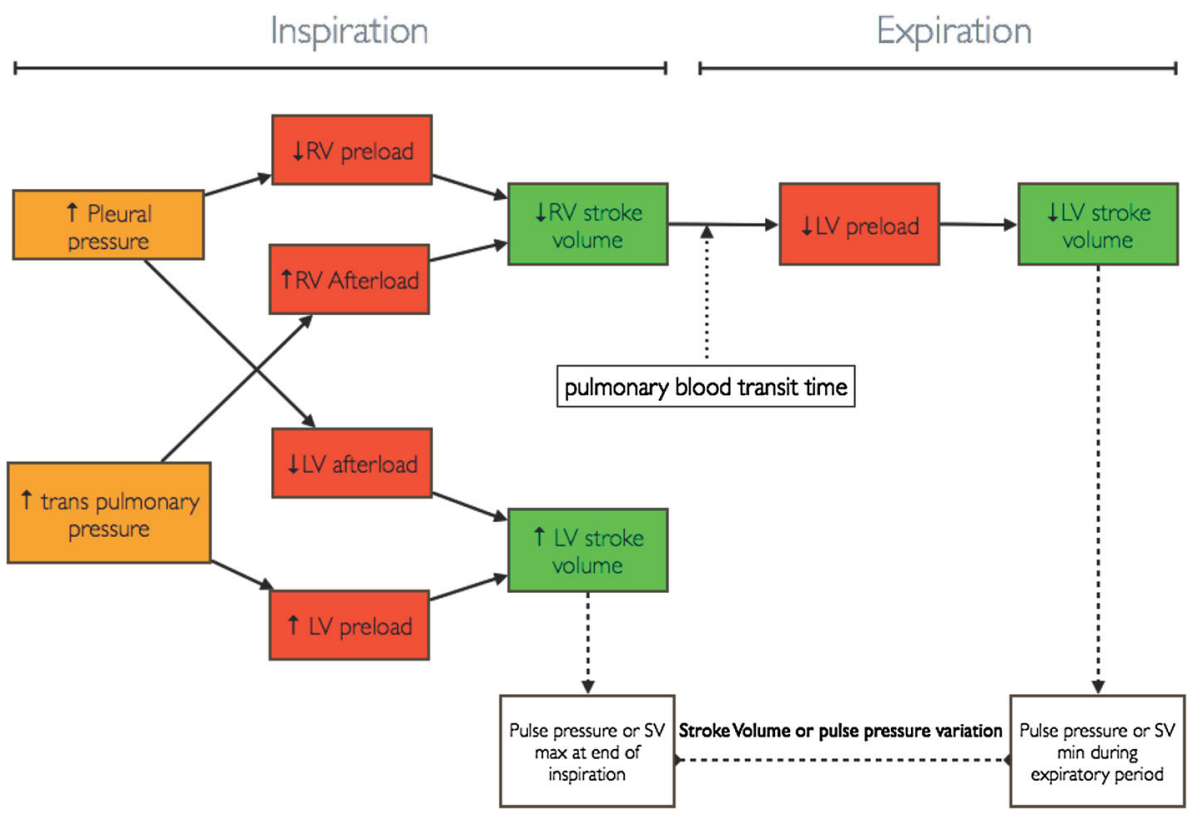

$14 \%$ with similar accuracy $[54,55]$. One of the potential benefits of using these parameters to guide fluid therapy is the avoidance of an unnecessary fluid challenge-one which demonstrates that the patient's stroke volume is already optimized and is not therefore fluid responsive. Waiting for the SVV to rise above $10 \%$ (or PPV above $14 \%$ ) allows clinicians to only give a fluid challenge when needed rather than to 'test' for fluid responsiveness by challenging the SV. These parameters, however, do require the patient to be mechanically ventilated with a tidal volume of $>7 \mathrm{ml} / \mathrm{kg}$, to be in sinus rhythm, and are inaccurate in subjects with right heart failure. In addition there is the 'grey zone' where subjects may or may not be fluid responsive [56]. Cannesson found that below a PPV of $9 \%$ only $11 \%$ of subjects increased their cardiac output significantly to a fluid bolus, whilst if the PPV was $>13 \%$ $91 \%$ of subjects showed a significant increase. However, in the grey zone (PPV 9-13\%) there was an equal proportion of responders and non responders. Theoretically, combining the grey zone approach ('definitely' fluid responsive vs. 'definitely' unresponsive) with the actual change in stroke volume or the change in PPV/SVV seen with any fluid challenge given to those 'grey zone' patients should improve the clinical utility of these monitors.

There are many studies, and indeed meta-analyses, reporting improved outcomes in patients undergoing major intra-abdominal surgery who receive haemodynamic optimization to improve global blood flow [27, 28, 41, 42]. The largest trial to date, the Optimise trial [57•], randomized 734 patients undergoing major gastrointestinal surgery (one third colorectal) to receive either arterial waveform based fluid optimization together with low dose inotrope (dopexamine) or standard care. Whilst there was a reduction in the primary outcome of moderate to major complications in the intervention group this was not statistically significant $(43.4$ vs. $36.6 \%, \quad \mathrm{RR}=0.86 \quad(95 \% \quad \mathrm{CI}$ $0.71-1.01), p=0.07)$. It is worth noting, however, that after adjustment (defined a priori) for protocol non-adherence the effect was strengthened to statistical significance $(\mathrm{RR}=0.80$ (95\% CI 0.61-0.99), $p=0.04)$ and similarly, when the first 10 patients from each recruiting centre were discounted to allow for the 'learning curve' with the monitoring equipment, again predefined in the protocol, the effect of the intervention was significant $(\mathrm{OR}=0.59$, (95\% CI 0.41-0.84)).

The authors also presented an updated meta-analysis of the impact of perioperative haemodynamic optimization confirming a significant reduction in postoperative complications $(\mathrm{RR}=0.77(0.71-0.83))$.

Despite this knowledge the uptake of haemodynamic monitoring amongst clinicians has been poor [58] even though it is now considered a standard of care in some countries [59]. A possible explanation for this reluctance to embrace the concept of haemodynamic optimization is the perceived potential for harm in terms of cardiac events. Indeed beta-blockade is advocated for cardiac protection in certain high risk patients undergoing major surgery $[60,61]$ and therefore the concept of 'driving' the myocardium with inotropes seems counterintuitive. In the Optimise trial 5 patients in the intervention group (1.4\%) suffered serious cardiac complications within $24 \mathrm{~h}$ of the intervention compared to none in the control group. By 30 days, however, there were no differences in cardiac outcome between the groups. This finding is in keeping with a recent meta- 
analysis of over 2,000 patients involved in 22 goal-directed therapy trials which showed a reduction in overall cardiac complications in the intervention group $(\mathrm{OR}=0.54$, $(0.38-0.76), p=0.0005)$ [62]. Our routine practice is to institute beta-blockade perioperatively in those patients with inducible ischaemia or evidence of poor functional capacity due to myocardial dysfunction on exercise testing (Class IIa recommendation [61]) but we would not hesitate to perform haemodynamic optimization on these patientsindeed it is this group of patients in whom providing optimal fluid therapy is of the utmost importance.

\section{Alternative 'Goals'}

Whilst minimally invasive cardiac output monitors may form the basis of fluid administration algorithms their use can be supplemented using several commonly measured parameters.

\section{Central Venous Oxygen Saturations- $-\mathrm{ScvO}_{2}$}

Central venous oxygen saturations reflect the balance between global oxygen delivery and consumption and low values have been associated with worse perioperative outcomes. Two trials to date have used central venous oxygen saturations to guide fluid therapy. In one trial, including 135 major intra-abdominal surgeries (including aortic surgery), an outcome benefit in terms of length of stay and complications was seen in the intervention group which received fluids and inotropes to target an oxygen extraction ratio of less than $27 \%$ [63]. In a second study by Jammer, 241 colorectal patients received either $\mathrm{ScvO}_{2}$ guided starch boluses or standard care consisting of relatively large infusions of crystalloid [64]. No difference in the incidence of postoperative complications was seen in this study. Both of these studies have weaknesses in that the control of factors that are known to affect $\mathrm{ScvO}_{2}$ such as blood transfusion and vasopressor use was not optimal.

The evidence to support central venous saturations as the sole guide to fluid therapy is weak, but it may have utility as an adjunct to inform the clinician that all is well at the tissue level.

\section{Lactate and Base Deficit}

Little research has been carried out on using these measures of tissue perfusion as therapeutic goals to guide haemodynamic therapy [5]. Certainly there is a well recognised association between abnormal values and worse post operative outcome [65, 66], and they are frequently reported as surrogates for outcome in major gastrointestinal surgery [67]. Hyperlactataemia has a low sensitivity for predicting poor outcome but a good specificity. Data taken from a recent trial in colorectal patients at our institution [22•] demonstrated that lactate levels measured $3 \mathrm{~h}$ postprocedure independently predicted major postoperative complications and prolonged hospital stay $(\mathrm{OR}=1.5$ (95\%CI 1.1-2.1) and 1.9(1.7-2.4) respectively, $p<0.05$ ) [68].

\section{Urine Output}

Urine output is variable during colorectal surgery for a variety of reasons and its use as a guide to intravenous fluid therapy cannot be recommended. The natural stress response to surgery is an increase in sympathetic tone and the release of cytokines, both of which cause release of antidiuretic hormone and aldosterone which reduce urine output by sodium and water retention. There is no relationship between intraoperative urine output and acute kidney injury [69].

\section{Microvascular Flow}

Recent interest has concentrated on the concept that simply increasing cardiac output to increase tissue oxygen delivery may not be the optimal way to ensure that oxygen is actually available at the cellular level. Techniques using dark field microscopy demonstrate that improving convection (flow) at the capillary level is only half the story. If too much fluid is administered the diffusive capacity of the microcirculation, measured by the functional capillary density, is reduced and despite adequate flow, oxygen transport from red blood cell to mitochondria is actually reduced. The recent introduction of handheld, bedside monitors of microvascular flow that can be used real time to guide fluid therapy will allow for this highly interesting (and possibly unifying) theory to be tested in clinical trials $[70,71 \bullet \bullet$.

\section{Laparoscopic Surgery}

Currently there is no evidence to suggest an alternative approach to intravenous fluid therapy is warranted in patients undergoing laparoscopic colorectal surgery. Despite longer operations [72], laparoscopic surgery is associated with less blood loss [73] and the lack of an open wound leads to less insensible losses (although the impact of evaporative losses through this route has probably been overstated [74]). Establishing a pneumoperitoneum or positioning a patient in the Trendelenberg or reverse Trendelenberg position can complicate the delivery of goal-directed fluid therapy using minimally invasive 
cardiac output monitors. Fluid shifts resulting from these manoeuvres may cause a relative change in stroke volume as measured by OD or waveform analysis although SVV as measured by the Flotrac/Vigileo system appears to be less affected [75]. These dynamic parameters should be measured before and after any position change. There is currently no evidence base to guide the clinician on how to respond to, for example, a drop in stroke volume caused by placing the patient in the steep head up position but most authorities would agree that as there has been no significant change in the overall volaemic status of the patient, it is illogical to try to correct that change purely with fluid. Most would advocate the judicious use of vasopressor and possibly the acceptance of slightly lower value. In these circumstances, other measures of tissue perfusion are invaluable.

\section{Fluid Types and Influences on Perioperative Outcomes}

\section{Crystalloid Versus Colloid?}

There are theoretical advantages to using colloid in patients undergoing major colorectal surgery due to the lower volume of fluid required to achieve haemodynamic optimization, and the detrimental effects of excess crystalloid solution, particularly on anastomoses. Marjanovic administered crystalloid infusions to rats for $30 \mathrm{~min}$ before and after a small bowel anastomosis was completed [76]. The animals received either 3 , 9, or $36 \mathrm{ml} / \mathrm{kg} / \mathrm{hr}$ (volume deplete, control, and volume overload groups) of crystalloid. The volume overload group had noticeable macroscopic gut oedema, a lower anastomotic bursting pressure, and evidence of less anastomotic stability. Kimberger examined the effects of GDT using either crystalloid or colloid on the local and regional blood flow in porcine colonic anastomoses [36]. The animals all received a background infusion of $3 \mathrm{ml} / \mathrm{kg} / \mathrm{hr}$ of Ringers lactate, and were randomised to receive either no additional fluid boluses (restricted RRL), or $250 \mathrm{ml}$ boluses of either ringers lactate (GDRL) or colloid (GDC) if $\mathrm{ScvO}_{2}$ fell below $60 \%$. Baseline $\mathrm{ScvO}_{2}$ was less than $60 \%$ in all animals, and remained so in the RRL group. After a single fluid bolus $\mathrm{ScvO}_{2}$ increased in all but one of the animals in the colloid group, however, this was not replicated in the GDRL group. There was no difference in mesenteric $\mathrm{pH}$, lactate or oxygen tension between the groups but there was an improvement seen in the GDC group with improved colonic and anastomotic oxygen tensions, as well as improved peri-anastomotic blood flow, when compared to the crystalloid group.

The majority of goal-directed therapy trials to date have used colloid boluses to optimize circulating volume [27]. This was done in the assumption that by using colloid a smaller volume of fluid could be administered to achieve the desired haemodynamic endpoint. Two trials have been carried out in the colorectal setting comparing the use of crystalloid with colloid for optimization.

Senagore randomised 64 patients undergoing laparoscopic colectomy to receive either standard crystalloid based fluid therapy, OD guided crystalloid or OD guided hydroxyethyl starch (HES) [21]. Despite more fluid being required intraoperatively in the OD guided crystalloid group there were no clinically significant differences between the groups in terms of hospital length of stay or complication rate.

In a larger study from our institution 202 patients were randomised to receive goal-directed balanced crystalloid or goal-directed balanced starch solution as haemodynamic optimistion fluid [22•]. Again, more fluid was required intraoperatively in the crystalloid group (3175 (2000-3700) vs. $1875 \mathrm{ml}(1500-3000), p<0.001)$ and the crystalloid group had a higher $24 \mathrm{~h}$ fluid balance $(+4226(3251-5779)$ vs. $+3610 \mathrm{ml}(2443-4519), p<0.001)$ but despite this no differences were observed between the groups in postoperative complications, return of gastrointestinal function, hospital length of stay or the magnitude of the inflammatory response as measured by $\mathrm{C}$-reactive protein and Interleukins 6 and 10.

These trials, in keeping with other recent studies, have disproved the theory that 3 times more crystalloid than colloid is needed to achieve haemodynamic endpoints with reported ratios being in the order of 1:1.5 [77, 78].

The use of HES has also been demonstrated in several large randomized controlled trials in critically ill patients to confer no outcome benefit and possibly harm, predominately in terms of renal dysfunction [79-81]. This safety concern does not seem to hold true in the perioperative setting, however, with two separate reviews demonstrating no deleterious effects $[82,83 \cdot]$. Despite this indications for using HES have been greatly restricted in Europe [84] and in the US the FDA have issued a Boxed warning over its use [85].

Overall, there do not appear to be any outcome benefits in using HES over crystalloids perioperatively and given its significantly higher cost its use cannot be recommended in this setting.

The use of gelatins as an alternative to HES cannot be recommended either given the lack of evidence supporting its safety or efficacy in the colorectal population. Gelatins also carry a significantly higher anaphylaxis rate than HES [86, 87].

Human albumin solution (HAS) could also be considered as an optimization fluid but its use is not widespread. Its use in cardiac surgery has declined significantly with more recent studies, once again, showing no benefit over crystalloid [88]. There is little evidence to support its use in the colorectal setting. 
Balanced Solutions Versus Normal Saline?

A 2012 meta-analysis of 13 randomized trials of buffered versus non-buffered fluids for perioperative fluid administration demonstrated that the use of buffered fluids resulted in fewer episodes of metabolic derangement such as hyperchloraemia and metabolic acidosis. There were no statistically significant differences in mortality or renal function, but there were also too few such events to draw reliable conclusions [89].

An observational study from the same year examining the type of fluid administered to nearly 32,000 patients on the day of surgery demonstrated a significant reduction in mortality ( 5.6 vs. $2.9 \%, p<0.001$ ), and complications including renal dysfunction, blood transfusion and postoperative infection, in those patients who received a balanced electrolyte solution (Plasma-Lyte) compared to normal saline alone [23•].

Whilst not strictly perioperative studies, two further reports in the Intensive Care setting highlight the importance of the composition of intravenous fluids. Yunos, in 2012, presented a 'before and after' pilot study investigating the impact of introducing a low-chloride based fluid resuscitation practice in a general ICU [90]. Chloride administration has been shown to cause renal vasoconstriction thereby reducing GFR and urine output in major surgery. In the 6 months following the introduction of balanced, low-chloride solutions (and the restriction of the use of chloride rich solutions to specific conditions such as brain injury or hyponatraemia) a $50 \%$ reduction in the incidence of acute kidney injury $(\mathrm{OR}=0.52(0.37-0.75)$ $p<0.001)$ and renal replacement therapy $(\mathrm{OR}=0.52$ $(0.33-0.81) p=0.004)$ was observed.

More recently, Raghunathan reported the impact of differing fluid regimes in a large observational series of adult patients with severe sepsis [91]. After propensity matching, those patients who were resuscitated in the ICU with balanced solutions had better outcomes in terms of hospital mortality (19.6 vs. $22.8 \%,(\mathrm{RR}=0.86(0.78-0.94))$ compared to those resuscitated with saline-based solutions. Whilst both of these studies convey a clear message about the benefit of using balanced solutions in Critical Care, in keeping with the perioperative meta-analysis, it should be noted that they are observational studies with the associated risks posed by confounding factors. Both sets of authors point this out clearly and call for further research in this area. Planning for large, multicentre RCT's of balanced versus saline-based fluid administration in the perioperative period is underway.

\section{Emergency Surgery}

Fluid management during emergency bowel surgery has been studied far less extensively than during elective surgery. Difficulty recruiting patients to studies in these circumstances [55] is understandable but disappointing given the far higher morbidity and mortality that is associated. Inflammatory or haemorrhagic processes are more pronounced and may lead to extensive fluid deficits and increased tissue oxygen demand. The fundamental observation behind GDT - that the inability to elevate oxygen delivery in critically ill surgical patients leads to worse outcomes [25] - means that strategies to optimize oxygen delivery in these patients must be paramount.

In this group the benefits of using a calibrated cardiac output monitoring system need further investigation.

\section{Conclusion}

Whilst some debate still exists about the best method for optimizing tissue oxygenation, the realization that this should be the goal of perioperative fluid therapy rather than simply the normalization of classically measured parameters such as blood pressure, heart rate, CVP, and urine output is a step forward. Further research focusing on the clinical utility of monitors of the microcirculation in colorectal surgery is an exciting and promising avenue. The possibility that this type of monitoring could supplement the established methods of ensuring an adequate cardiac output could help clinicians improve the way in which they administer intravenous fluids in order to achieve adequate tissue oxygenation without the risk of over-resuscitation.

Acknowledgments This article was reviewed by Dr. Martin J. London of the University of California, San Francisco.

\section{Compliance with Ethics Guidelines}

Conflict of Interest David R.A. Yates, Simon J. Davies, Samantha R. Warnakulasuriya, and R. Jonathan T. Wilson declare that they have no conflict of interest.

Human and Animal Rights and Informed Consent This article does not contain any studies with human or animal subjects performed by any of the authors.

\section{References}

Papers of particular interest, published recently, have been highlighted as:

- Of importance

•• Of major importance.

1. Guyton AC. Textbook of medical physiology, vol. 8. Philadelphia: WB Saunders; 1991.

2. Clowes GHA Jr, Del Guercio LRM. Circulatory response to trauma of surgical operations. Metabolism. 1960;9:67-81. 
3. Bellamy MC. Wet, dry or something else? $\mathrm{Br} \mathrm{J}$ Anaesth. 2006;97:755-7.

4. Futier E, Constantin J-M, Petit A, et al. Conservative vs restrictive individualized goal-directed fluid replacement strategy in major abdominal surgery. A prospective trial. Arch Surg. 2010;145:1193-200.

5. Wenkui Y, Ning L, Jianfeng G, et al. Restricted perioperative fluid administration adjusted by serum lactate level improved outcome after major elective surgery for gastrointestinal malignancy. Surgery. 2010;147:542-52.

6. Nisanevich V, Felsenstein I, Almogy G, et al. Effect of intraoperative fluid management on outcome after intraabdominal surgery. Anesthesiol. 2005;103:25-32.

7. Brandstrup B, Tonnesen H, Beier-Holgersen R, et al. Effects of intravenous fluid restriction on postoperative complications: comparison of two perioperative fluid regimens: a randomized assessor-blinded multicenter trial. Ann Surg. 2003;238:641-8.

8. Girish PJ. Intraoperative fluid restriction improves outcome after major elective gastrointestinal surgery. Anesth Analg. 2005;101: $601-5$.

9. Holte K, Foss NB, Andersen J, et al. Liberal or restrictive fluid administration in fast-track colonic surgery: a randomized, double-blind study [Erratum appears in $\mathrm{Br} \mathrm{J}$ Anaesth $2008 \mathrm{Feb}$; 100(2):284]. Br J Anaesth. 2007;99:500-8.

10. Lobo DN, Bostock KA, Neal KR, et al. Effect of salt and water balance on recovery of gastrointestinal function after elective colonic resection: a randomised controlled trial. Lancet. 2002; 359:1812-8.

11. Vermeulen H, Hofland J, Legemate DA, Ubbink DT. Intravenous fluid restriction after major abdominal surgery: a randomized blinded clinical trial. Trials. 2009;10:50.

12. Brandstrup B, Svendsen PE, Rasmussen M, et al. Which goal for fluid therapy during colorectal surgery is followed by the best outcome: near-maximal stroke volume or zero fluid balance? Brit J Anaes. 2012;109(2):191-9.

13. Wilson J, Woods I, Fawcett J, et al. Reducing the risk of major elective surgery: randomised controlled trial of preoperative optimisation of oxygen delivery. BMJ. 1999;318(7191): 1099-103.

14. Boyd OO, Grounds RM, Bennett ED. A randomized clinical trial of the effect of deliberate perioperative increase of oxygen delivery on mortality in high-risk surgical patients. JAMA. 1993;270(22):2699-707.

15. Wakeling HG. Intraoperative oesophageal Doppler guided fluid management shortens postoperative hospital stay after major bowel surgery. Brit J Anaesth. 2005;95(5):634-42.

16. Noblett SE, Snowden CP, Shenton BK, Horgan AF. Randomized clinical trial assessing the effect of Doppler-optimized fluid management on outcome after elective colorectal resection. Brit $\mathbf{J}$ Surg. 2006;93(9):1069-76.

17. Srinavasa S, Taylor MHG, Singh PP, et al. Randomized clinical trial of goal-directed fluid therapy within an enhanced recovery protocol for elective colectomy. Brit J Surg. 2012;100(1):66-74.

18. Gan TJ, Soppitt A, Maroof M, et al. Goal-directed intraoperative fluid administration reduces length of hospital stay after major surgery. Anesthesiol. 2002;97(4):820-6.

19. Conway DH, Mayall R, Abdul-Latif MS, et al. Randomised controlled trial investigating the influence of intravenous fluid titration using oesophageal Doppler monitoring during bowel surgery. Anaesthesia. 2002;57:845-9.

20. Pearse R, Dawson D, Fawcett J, et al. Early goal-directed therapy after major surgery reduces complications and duration of hospital stay. A randomised, controlled trial. Crit Care. 2005;9: R687-93.

21. Senagore AJ, Emery T, Luchtefeld M, et al. Fluid management for laparoscopic colectomy: a prospective, randomized assessment of goal-directed administration of balanced salt solution or Hetastarch coupled with an enhanced recovery program. Dis Colon Rectum. 2009;52:1935-40.

22. - Yates, DRA, Davies, SJ, Milner HE and Wilson RJT. Crystalloid or colloid for goal-directed fluid therapy in colorectal surgery. Brit Jour Anaesth 2014;112(2):281-9 The largest balanced crystalloid $v$ colloid trial to date with good standardization of other aspects of perioperative care.

23. - Shaw AD, Bagshaw SM, Goldstein SL, et al. Major complications, mortality, and resource utilization after open abdominal surgery: $0.9 \%$ saline compared to Plasma-Lyte. Ann Surg 2012;255(5):821-9 This very large observational trial provides compelling argument in the balanced $v$ saline based debate. Many confounders have been taken into account in the trial design leaving a very clear message.

24. Wilkes NJ, Woolf R, Mutch M, et al. The effects of balanced versus saline-based hetastarch and crystalloid solutions on acidbase and electrolyte status and gastric mucosal perfusion in elderly surgical patients. Anesth Analg. 2001;93:811-6.

25. Shoemaker WC, Appel PL, Kram HB. Role of oxygen debt in the development of organ failure sepsis, and death in high-risk surgical patients. Chest. 1992;102(1):208-15.

26. Shoemaker WC. Prospective trial of supranormal values of survivors as therapeutic goals in high-risk surgical patients. Chest. 1988;94(6):1176-86.

27. Giglio MT, Marucci M, Testini M, Brienza N. Goal-directed haemodynamic therapy and gastrointestinal complications in major surgery: a meta-analysis of randomized controlled trials. Brit J Anaesth. 2009;103(5):637-46.

28. Grocott MP, Dushianthan A, Hamiltom MA, et al. Perioperative increase in global blood flow to explicit defined goals and outcomes after surgery: a Cochrane systematic review. Brit J Anaesth. 2013;111(4):535-48.

29. Price HL, Deutsch S, Marshall BE, et al. Hemodynamic and metabolic effects of hemorrhage in man, with particular reference to the splanchnic circulation. Circ Res. 1966;18(5):469-74.

30. Chieveley-Williams S, Hamilton-Davies C. The role of the gut in major surgical postoperative morbidity. Int Anesthesiol Clin. 1999;37(2):81-110.

31. Silva JM, de Oliveira AM, Nogueira FA, Vianna PM, et al. The effect of excess fluid balance on the mortality rate of surgical patients: a multicenter prospective study. Crit Care. 2013;17(6): R288.

32. Doherty M, Buggy DJ. Intraoperative fluids: how much is too much? Brit J Anaesth. 2012;109(1):69-79.

33. Lowell JA, Schifferdecker C, Driscoll DF, et al. Postoperative fluid overload: not a benign problem. Crit Care Med. 1990;18: $728-33$.

34. Holte K, Sharrock NE, Kehlet H. Pathophysiology and clinical implications of perioperative fluid excess. $\mathrm{Br} \mathrm{J}$ Anaesth. 2002;89:622-32.

35. Arieff AI. Fatal postoperative pulmonary edema: pathogenesis and literature review. Chest. 1999;115:1371-7.

36. Kimberger O, Arnberger M, Brandt S, et al. Goal-directed colloid administration improves the microcirculation of healthy and perianastomotic colon. Anesthesiol. 2009;110(3):496-504.

37. Hiltebrand LB, Kimberger O, Arnberger M, et al. Crystalloids versus colloids for goal-directed fluid therapy in major surgery. Crit Care. 2009;13(2):R40.

38. O'Mara MS, Slater H, Goldfarb IW, Caushaj PF. A prospective, randomized evaluation of intra-abdominal pressures with crystalloid and colloid resuscitation in burn patients. J Trauma. 2005;58(5):1011-8.

39. Balogh Z, McKinley BA, Cocanour CS. Supranormal trauma resuscitation causes more cases of abdominal compartment syndrome. Arch Surg. 2003;138(6):637-42. 
40. James MF. Fluid therapy and coagulation. TATM. 2003;5(4): 406-14.

41. Hamilton MA, Cecconi M, Rhodes A. A systematic review and meta-analysis on the use of preemptive hemodynamic intervention to improve postoperative outcomes in moderate and high-risk surgical patients. Anesth Analg. 2011;112(6):1392-402.

42. Gurgel ST, do Nascimento P Jr. Maintaining tissue perfusion in high-risk surgical patients. Anesth Analg. 2011;112(6):1384-91.

43. Bundgaard-Neilsen M, Secher NH, Kehlet H. 'Liberal' vs. 'restrictive' perioperative fluid therapy - a critical assessment of the evidence. Acta Anaesth. Scan. 2009;53(7):843-51.

44. Corcoran T, Rhodes JEJ, Clarke S, et al. Perioperative fluid management strategies in major surgery: a stratified meta-analysis. Anesthes Analg. 2012;114(3):640-51.

45. Rhodes A, Cecconi M, Hamilton M, et al. Goal-directed therapy in high-risk surgical patients: a 15-year follow-up study. Int Care Med. 2010;36(8):1327-32.

46. Sandham JD, Hull RD, Brant RF, et al. A randomized, controlled trial of the use of pulmonary-artery catheters in high-risk surgical patients. New Eng J Med. 2003;348(1):5-14.

47. Gattinoni L, Brazzi L, Pelosi P, et al. A trial of goal-oriented hemodynamic therapy in critically ill patients. New Eng J Med. 1995;333(16):1025-32.

48. Hayes MM, Timmins AC, Yau EH, et al. Elevation of systemic oxygen delivery in the treatment of critically ill patients. New Eng J Med. 1994;330(24):1717-22.

49. Challand C, Struthers R, Sneyd JR, et al. Randomized controlled trial of intraoperative goal-directed fluid therapy in aerobically fit and unfit patients having major colorectal surgery. Brit $\mathbf{J}$ Anaes. 2011;108(1):1-10.

50. Dabaghi SF, Rokey R, Rivera JM, et al. Comparison of echocardiographic assessment of cardiac hemodynamics in the intensive care unit with right-sided cardiac catheterization. Am J Cardiol. 1995;76:392-5.

51. Burtenshaw AJ, Isaac JL. The role of trans-oesophageal echocardiography for perioperative cardiovascular monitoring during orthotopic liver transplantation. Liver Transpl. 2006;12(11): 1577-83.

52. Benes J, Chytra I, Altmann P, et al. Intraoperative fluid optimization using stroke volume variation in high risk surgical patients: results of prospective randomized study. Crit Care. 2010;14(3):R118.

53. Zhang J, Qiao H, He Z, et al. Intraoperative fluid management in open gastrointestinal surgery: goal-directed versus restrictive. Clinics. 2012;67(10):1149-55.

54. Cannesson MM, Musard H, Desebbe O, et al. The ability of stroke volume variations obtained with vigileo/flotrac system to monitor fluid responsiveness in mechanically ventilated patients. Anesth Analg. 2009;108(2):513-7.

55. Berkenstadt H, Margalit N, Hadani M, et al. Stroke volume variation as a predictor of fluid responsiveness in patients undergoing brain surgery. Anesth Analg. 2001;92:984-9.

56. Cannesson MM, Le Manach YY, Hofer CK, et al. Assessing the diagnostic accuracy of pulse pressure variations for the prediction of fluid responsiveness: a "gray zone" approach. Anesthesiol. 2011;115(2):231-41.

57. - Pearse RM, Harrison DA, MacDonald N, et al. Effect of a perioperative, cardiac output-guided hemodynamic therapy algorithm on outcomes following major gastrointestinal surgery: a randomized clinical trial and systematic review. JAMA 2014;311(21):2181-90 This is the largest multicenter RCT of its kind examining the effects of GDT in the perioperative period. Whilst the results do not reach statistical significance the trial is of major importance in this area.

58. Cannesson MM, Pestel G, Ricks C, et al. Hemodynamic monitoring and management in patients undergoing high risk surgery: a survey among North American and European anesthesiologists. Crit Care. 2011;15(4):R197.

59. NHS Improvement and Efficiency Directorate. Innovation, Health and Wealth. Department of Health, 2011.

60. London MJ, Hur K, Schwartz GG, Henderson WG. Association of perioperative $\beta$-blockade with mortality and cardiovascular morbidity following major noncardiac surgery. JAMA. 2013; 309(16):1704-13.

61. Fleisher LA, Beckman JA, Brown KA, et al. 2009 ACCF/AHA focused update on perioperative beta blockade incorporated into the ACC/AHA 2007 guide- lines on perioperative cardiovascular evaluation and care for noncardiac surgery: a report of the American college of cardiology foundation/American heart association task force on practice guidelines. Circulation. 2009;120(21):e169-276.

62. Arulkumaran N, Corredor C, Hamilton MA, et al. Cardiac complications associated with goal-directed therapy in high-risk surgical patients: a meta-analysis. Brit J Anaes. 2014;112(4): 648-59.

63. Donati A, Loggi S, Preiser JC, et al. Goal-directed intraoperative therapy reduces morbidity and length of hospital stay in high-risk surgical patients. Chest. 2007;132(6):1817-24.

64. Jammer II, Ulvik AA, Erichsen CC, et al. Does central venous oxygen saturation-directed fluid therapy affect postoperative morbidity after colorectal surgery? A randomized assessor-blinded controlled trial. Anesthesiol. 2010;113(5):1072-80.

65. Husain FA, Martin MJ, Mullenix PS, et al. Serum lactate and base deficit as predictors of mortality and morbidity. Am J Surg. 2003;185(5):485-91.

66. McNelis J, Marini CP, Jurkiewicz A, et al. Prolonged lactate clearance is associated with increased mortality in the surgical intensive care unit. Am J Surg. 2001;182(5):481-5.

67. Forget P, Lois F, de Kock M. Goal-directed fluid management based on the pulse oximeter-derived pleth variability index reduces lactate levels and improves fluid management. Anesth Analg. 2010;111:910-4.

68. Lasithiotakis K, Wilson RJT, Davies SJ, et al. Three hour postoperative arterial lactate is an independent predictor of postoperative outcomes following elective colorectal surgery. Abstract presentation European Society Coloproctologists $24^{\text {th }}$ Sept 2014.

69. Kheterpal S, Tremper KK, Englesbe MJ, et al. Predictors of postoperative acute renal failure after noncardiac surgery in patients with previously normal renal function. Anesthesiol. 2007;107:892-902.

70. Jhanji S, Lee C, Watson D, et al. Microvascular flow and tissue oxygenation after major abdominal surgery: association with post-operative complications. Int Care Med. 2008;35(4):671-7.

71. •- Ince C. The rationale for microcirculatory guided fluid therapy. Curr Opin Crit Care 2014;20:301-8 A fascinating introduction and review of a relatively new method for assessing tissue oxygen delivery. Possibly a unifying theory for many aspects of organ dysfunction in critically ill patients.

72. Guillou PJ, Quirke P, Thorpe H, et al. Short-term endpoints of conventional versus laparoscopic-assisted surgery in patients with colorectal cancer (MRC CLASICC trial): multicentre, randomised controlled trial. The Lancet. 2005;365(9472):1718-26.

73. Kiran RP, Delaney CP, Senagore AJ, et al. Operative blood loss and use of blood products after laparoscopic and conventional open colorectal operations. Arch Surg. 2004;139(1):39-42.

74. Brandstrup B, Svendsen C, Engquist A. Hemorrhage and operation cause a contraction of the extra cellular space needing replacement-evidence and implications? A systematic review. Surgery. 2006;139:419-32.

75. Hoiseth LO, Hoff IE, Myre K, et al. Dynamic variables of fluid responsiveness during pneumoperitoneum and laparoscopic surgery. Acta Anaesth Scand. 2012;56(6):777-86. 
76. Marjanovic G, Villain C, Juettner E, et al. Impact of different crystalloid volume regimes on intestinal anastomotic stability. Ann Surg. 2009;249:181-5.

77. James MFMM, Michell WL, Joubert IA, et al. Resuscitation with hydroxyethyl starch improves renal function and lactate clearance in penetrating trauma in a randomized controlled study: the FIRST trial (Fluids in Resuscitation of Severe Trauma). Brit J Anaes. 2011;107(5):693-702.

78. Finfer S, Bellomo R, Boyce N, et al. A comparison of albumin and saline for fluid resuscitation in the intensive care unit. N Engl J Med. 2004;350:2247-56.

79. Perner A, Haase N, Guttormsen AB, et al. Hydroxyethyl starch 130/0.42 versus Ringer's acetate in severe sepsis. N Engl J Med. 2012;367:124-34.

80. Myburgh JA, Finfer S, Bellomo R, et al. Hydroxyethyl starch or saline for fluid resuscitation in intensive care. N Engl J Med. 2012;367:1901-11.

81. Brunkhorst FM, Engel C, Bloos F, et al. Intensive insulin therapy and pentastarch resuscitation in severe sepsis. N Engl J Med. 2008;358(2):125-39.

82. Gillies MA, Habicher M, Jhanji S, et al. Incidence of postoperative death and acute kidney injury associated with iv $6 \%$ hydroxyethyl starch use: systematic review and meta-analysis. Brit J Anaes. 2014;112(1):25-34.

83. - Van Der Linden P, James MFMM, Mythen M and Weiskopf, RB. Safety of Modern Starches Used During Surgery. Anesth Analg 2013;116(1):35-48 An excellent review of the common perceived problems associated with the modern starches.

84. European Medicines Agency. Hydroxyethyl-starch solutions (HES) no longer to be used in patients with sepsis or burn injuries or in critically ill patients. EMA/809470/2013. 19/12/2013.
85. US Food and drug administration. Hydroxyethyl Starch Solutions: FDA Safety Communication-Boxed Warning on Increased Mortality and Severe Renal Injury and Risk of Bleeding. Posted 06/11/2013.

86. Laxenaire MC, Charpentier C, Feldman L. Anaphylactoid reactions to colloid plasma substitutes: incidence, risk factors, mechanisms. A French multicenter prospective study. Ann Fr Anesth Reanim. 1994;13:301-10.

87. Harper NJN, Dixon T, Dugué P, et al. Suspected anaphylactic reactions associated with anaesthesia. Anaesthesia. 2009;64: 199-211.

88. Skhirtladze K, Base EM, Lassnigg A, et al. Comparison of the effects of albumin 5\%, hydroxyethyl starch 130/0.4 6\%, and Ringer's lactate on blood loss and coagulation after cardiac surgery. Brit J Anaes. 2014;112(2):255-64.

89. Burdett E, Dushianthan A, Bennett-Guerrero E, et al. Perioperative buffered versus non-buffered fluid administration for surgery in adults. Cochrane Database Syst Rev. 2012;12:CD004089.

90. Yunos NM, Bellomo R, Hegarty C, et al. Association between a chloride-liberal vs chloride-restrictive intravenous fluid administration strategy and kidney injury in critically ill adults. JAMA. 2012;308(15):1566-72.

91. Raghunathan K, Shaw A, Nathanson B, et al. Association between the choice of IV crystalloid and in-hospital mortality among critically Ill adults with sepsis. Crit Care Med. 2014;42(7):1585-91. 